\title{
Preface to the Special Issue: Aerosols, Clouds, Radiation, Precipitation, and Their Interactions
}

\author{
Xiquan $\mathrm{DONG}^{1,2}$ \\ ${ }^{1}$ Institute of Heavy Rain, China Meteorological Administration, Hubei Key Laboratory for \\ Heavy Rain Monitoring and Warning Research, Wuhan 430205, China \\ ${ }^{2}$ Department of Hydrology and Atmospheric Sciences, University of Arizona, \\ Tucson, AZ 85721, USA
}

Citation: Dong, X. Q., 2018: Preface to the special issue: Aerosols, clouds, radiation, precipitation, and their interactions. Adv. Atmos. Sci., 35(2), 133-134, https://doi.org/10.1007/s00376-017-7007-4.

The treatment of aerosols, clouds, radiation, and precipitation in climate models, in addition to their interactions and associated feedbacks, has long been one of the largest sources of uncertainty in predicting any potential future climate changes. Although many improvements have been made in CMIP5, aerosols, clouds, radiation, and their feedbacks are still a problem in climate models, as concluded in IPCC AR5 and published papers. Many studies have shown that modeled aerosols, clouds, radiation, and precipitation agree with observations within a certain range on a global scale; however, large biases occur at the regional scale. Characterizing the effects of aerosols and clouds on energy and the hydrological cycle and understanding the interactions among aerosols, clouds, radiation, and precipitation, are critical for weather forecasting and climate models. Significant improvements are needed, which require advanced observations and modeling at a range of spatial and temporal scales.

This special issue has solicited a total of 11 papers to cover a broad scope of research topics, which can be briefly summarized in the following three major areas: aerosol properties; aerosol effects and impacts; cloud condensation nuclei $(\mathrm{CCN})$, cloud and precipitation properties. The aerosol properties include the aerosol optical properties derived from Cimel sunphotometer data (Mai et al., Page 195-208), growth rates of fine aerosol particles from ground-based remote sensors (Zhao et al., Page 209-217), and the trends of aerosol optical depth over land from MODIS observations (Fan et al., Page 135-145). The aerosol effects and impacts consist of the aerosol indirect effect over China using ground-based observations (Liu and Li, Page 169-181), aerosol direct and indirect effects and auto-conversation processes over the West African monsoon region using a regional climate model (Salah et al., Page 182-194), aerosol properties and their impacts on surface CCN based on the US DOE Atmospheric Radiation Measurements (ARM) Southern Great Plains (SGP) surface observations (Logan et al., 224-233), and aerosol impacts on continental clouds through WRF simulations (Wang et al., Page 234-247). The last section covers the surface CCN over the Bay of Bengal (Chate et al., Page 218-223), cloud coverage over northern China from both satellite and surface observations (Zhang et al., Page 146-157), a climatology of cloud-base height derived from radiosonde measurements (Zhang et al., Page 158-168), and implementation of new cloud microphysical parameterizations in a GCM (Xie et al., Page 248-259).

In particular, Mai et al. (Page 195-208) examined aerosol optical properties and direct radiative effects on surface irradiance using seven years (2006-2012) of Cimel sunphotometer data collected at Panyu in the Pearl River Delta (PRD) region of China. They found that about $90 \%$ of aerosols are dominated by fine-mode strongly absorbing particles during the dry season (October to February). The mean shortwave aerosol radiative forcings at the surface, in the atmosphere, and at the top of the atmosphere, were $-33.4 \pm 7.0,26.1 \pm 5.6$ and $-7.3 \pm 2.7 \mathrm{~W} \mathrm{~m}^{-2}$, respectively. Zhao et al. (Page 209-217) investigated the growth of fine aerosol particles during the AC3E (Aerosol-CCN-Cloud 22 Closure Experiment) campaign in June 2013 at an urban site near Beijing. The mechanisms that can affect the growth of fine aerosol particles are also discussed. Fan et al. (Page 135-145) performed an extensive analysis to assess the representativeness of the long-term trends of aerosol optical depth derived from the Moderate Resolution Imaging Spectroradiometer (MODIS) sensor onboard the Aqua satellite. Using Aerosol Robotic Network (AERONET) observations as a ground-truth, they found that the trends measured by AERONET can be reproduced by MODIS observations, with particularly good agreement over Europe and North America. However, caution should be exercised for a few sites in Australia and South America because of some notable disagreements that exist between the two datasets.

Liu and Li (Page 169-181) provided a first estimation of the aerosol indirect effect in southeastern China using a unique surface-based dataset. The aerosol first indirect effect is estimated in terms of relative changes in both cloud droplet effective radius and cloud optical depth with changes in aerosol index for different seasons and air masses. Salah et al. (Page 182-194) investigated the direct and indirect effects of natural and anthropogenic aerosols (e.g., black carbon and sulfate) over West and Central Africa during the West African monsoon period. They also examined the sensitivity of the long-standing issue of 
the wet bias in RegCM to different formulations of auto-conversion parameterizations. They found that the Beheng scheme reduces the precipitation wet bias by more than $50 \%$ over West Africa and achieves a bias reduction of around $25 \%$ over Central Africa. The aerosol-induced radiative forcing varied considerably (ranging from -5 to $-25 \mathrm{~W} \mathrm{~m}^{-2}$ ) with different autoconversion schemes. Logan et al. (Page 224-233) studied the dependence of CCN number concentration on aerosol type and transport pathways using the DOE ARM SGP observations and found a common transport mechanism for smoke aerosols and moisture via the Gulf of Mexico, which explains the strong dependence of aerosol loading at SGP on air mass type.

Wang et al. (Page 234-247) used an aerosol-aware WRF model to investigate the microphysical and radiative effects of aerosols during the March 2000 Cloud Intensive Observational Period campaign at the US DOE ARM SGP site. Various effects of aerosols, including microphysical and semi-direct influences, were identified and discussed in the paper.

The final set of papers deals with cloud and precipitation properties with respect to CCN. Chate et al. (Page 218-223) examined the diurnal variation in $\mathrm{CCN}$ distributions at supersaturation from $0.2 \%$ to $1 \%$ collected during the first $\mathrm{CCN}$ measurements onboard the research vessel Sagar Kanya (cruise SK-296). The area covered from the south to the bay-head of the Bay of Bengal as part of the Continental Tropical Convergence Zone project during the Indian summer monsoon of 2012. The diurnal variation showed a two-peak pattern: CCN first peaks between 0600 and 0700 LST, with relatively lower concentrations between 1200 and 1400 LST, and a second peak around 1800 LST. Zhang et al. (Page 146-157) documented detailed intercomparison results on cloud cover, observed by the surface observers at synoptic meteorological stations and by MODIS. Based on 11-year daytime data and 7-year nighttime data over the North China Plain and its surrounding regions, they concluded that the cloud coverage derived from MODIS correlates well with the data from surface observers in summer than in winter. Overall, the MODIS-derived cloud coverage was $~ 15 \%$ higher than the surface-observed one, which may stem from issues related to the satellite viewing angle, aerosols, and snow cover. Zhang et al. (Page 158-168) presented a climatology of cloud-base height based on long-term radiosonde measurements in China, and concluded that the cloud-base heights are highest in summer, followed by those in spring and fall, with the lowest ones observed in winter. Finally, Xie et al. (Page 248-259) implemented cloud microphysical schemes including two-moment schemes: the cloud droplet effective radius $\left(R_{\mathrm{e}}\right)$ and the autoconversion process of cloud droplets to raindrops $\left(A_{\mathrm{r}}\right)$ and considering the relative dispersion of the cloud droplet size distribution into version 4.1 of the Institute of Atmospheric Physics' atmospheric GCM (IAP AGCM 4.1). They found that the newly implemented schemes can improve both the simulated shortwave and longwave cloud radiative forcings, as compared to the standard scheme, in IAP AGCM 4.1. Moreover, the new schemes can also impact the global distribution of precipitation, especially over low latitudes, although the influence on total precipitation is insignificant.

The 11 papers published in this special issue (February 2018) of Advances in Atmospheric Sciences provide valuable datasets from ground-based and satellite remote sensing, as well as from modeling efforts, for scientists to further study aerosol and cloud properties and their effects and impacts on radiation and precipitation.

Acknowledgements. It would have been impossible to produce this special issue without the significant contributions of the following guest editors: Jiwen FAN (Pacific Northwest National Laboratory, USA), Huiwen XUE (Peking University, China), Christine CHIU (University of Reading, UK), Yangang LIU (Brookhaven National Laboratory, USA), Chuanfeng ZHAO (Beijing Normal University, China), Zhibo ZHANG (University of Maryland, USA), Byung-Ju SOHN (Seoul National University, Korea), and Teruyuki NAKAJIMA (Japan Aerospace Exploration Agency, Japan). NAKAJIMA is the Secretary General of International Association of Meteorology and Atmospheric Sciences (IAMAS). SOHN is the President of International Radiation Commission, IAMAS. The lead editor, DONG, was primarily supported by the Major International (Regional) Joint Research Project of the National Science Foundation of China (NSFC) (Grant No. 41620104009) at the Institute of Heavy Rain. The editorial team appreciates the above projects and organizations for their contribution to this special issue. 